\title{
Effectiveness of surgical treatment in chronic migraine
}

\author{
Eficacia del tratamiento quirúrgico en la migraña crónica
}

\author{
Francisco Javier Amaya-Blas', Gabriel A. Mecott ${ }^{*}$, Alejandro Marfil-Rivera², \\ María de Lourdes Tamayo-Esquiveß ${ }^{3}$, Mauricio Manuel García-Pérez¹, Hernán Chacón-Moreno', \\ Sergio Pérez-Porras ${ }^{1}$, Rosa Coutiño ${ }^{1}$ and Yanko Castro-Góvea ${ }^{1}$ \\ ${ }^{1}$ Servicio de Cirugía Plástica, Estética, Reconstructiva y Maxilofacial; ${ }^{2}$ Servicio de Neurología; ${ }^{3}$ Servicio de Anestesiología. Hospital Universitario \\ Dr. José Eleuterio González, Universidad Autónoma de Nuevo León, Monterrey, N.L., Mexico
}

\begin{abstract}
Objective: Migraine affects more than 35 million people in the United States of America, and 10\% of the population in the world. The purpose of this study was to evaluate the effectiveness of surgical treatment in chronic migraine with frontal or occipital trigger areas. Methods: We designed a pilot, proof of concept, and prospective study to analyze the effectiveness of surgical release of trigger nerves in severe frontal or occipital chronic migraines. The study was approved by the Ethics and Investigation Committee of Hospital Universitario Dr. José Eleuterio González (Monterrey, N.L., Mexico). We included patients diagnosed with chronic migraine by the neurology service of Hospital Universitario Dr. José Eleuterio González that attended our consult from March to December 2012. The patients were assessed by the MIDAS questionnaire and the diagnosis confirmed by injecting $2 \%$ lidocaine in the trigger sites. We realized a superior palpebral approach in frontal migraines to resection the glabellar muscles and an occipital approach to free the greater occipital nerve bilaterally. We evaluated complete and partial clinical response measuring the frequency, intensity, and duration of migraine episodes. Results: We included three patients with Stage IV (severe incapacitating) frontal or occipital chronic migraines. Two were occipital trigger sites and one frontal. We obtained complete clinical response in two patients and a partial response in one. Pain intensity decreased in all patients. Conclusion: Surgical treatment is effective in Stage IV (severe incapacitating) frontal or occipital trigger chronic migraines.
\end{abstract}

KEY WORDS: Migraine. Surgical treatment. Triggers.

\section{Resumen}

Objetivos: La migraña crónica afecta a más de 35 millones de personas en los EE.UU. y al 10\% de la población en México. El objetivo de este estudio fue valorar la efectividad del tratamiento quirúrgico en la migraña crónica con sitios detonantes frontal u occipital para proponerla como alternativa quirúrgica en nuestro medio. Método: Se incluyeron pacientes con diagnóstico de migraña crónica con sitios detonantes frontal u occipital valorados por el servicio de neurología del Hospital Universitario Dr. José Eleuterio González (Monterrey, N.L., México) que acudieron a consulta de marzo a diciembre de 2012, con la autorización del Comité de Ética e Investigación. Se valoraron mediante el cuestionario MIDAS, y los sitios gatillo se

\author{
Correspondence: \\ *Gabriel A. Mecott, \\ Servicio de Cirugía Plástica Estética, \\ Reconstructiva y Maxilofacial \\ Hospital Universitario Dr. José Eleuterio González \\ Universidad Autónoma de Nuevo León \\ Monterrey, N.L., México \\ E-mail: gabriel.mecottrv@uanl.edu.mx
}

Fecha de recepción: 27-01-2018

Fecha de aceptación: 14-02-2018

DOI://dx.doi.org/10.24875/CIRU.M18000009
Cir Cir. 2018;86:99-104

Disponible en PubMed www.cirugiaycirujanos.com 
confirmaron con la inyección de lidocaína al $2 \%$. Se realizó un abordaje en el surco palpebral superior para liberar los músculos corrugadores y procerus en caso de detonante frontal, y un abordaje occipital para liberar el nervio occipital mayor bilateral. Se valoró la respuesta clínica total y parcial según la intensidad, la frecuencia y la duración de los episodios migrañosos mensuales. Resultados: Se incluyeron tres pacientes con migraña crónica en etapa IV (incapacidad grave), a los que correspondían dos sitios detonantes frontal y uno occipital. Obtuvimos dos pacientes con respuesta clínica completa y una con respuesta parcial. La intensidad del dolor mejoró en todos los pacientes. Conclusiones: El tratamiento quirúrgico es efectivo en la migraña crónica con sitios detonantes frontal u occipital en pacientes con incapacidad grave.

PALABRAS CLAVE: Migraña. Tratamiento quirúrgico. Desencadenantes.

\section{Introduction}

Migraine affects more than 35 million people in the United States of America and $10 \%$ of the population in the world. It is twice more common in women than in men and typically affects economically active populations (ages 20-50 years old). Approximately a quarter of US households have a member with migraine. ${ }^{1}$ Migraine symptoms interfere with common day activities, and they include throbbing pain, nausea, vomiting, photophobia, and phonophobia ${ }^{2}$.

Annual costs for medications can be as much as 1.5 billion dollars per year, and burden of days missing from work is up to 13 billion dollars ${ }^{3}$. The majority of cases are treated with a combination of non-pharmacologic and pharmacologic therapies. Pharmacologic treatment typically consists of non-steroidal anti-inflammatory drugs or a combination of acetaminophen, acetylsalicylic acid, and caffeine. Other commonly used drugs include sumatriptan and ketorolac ${ }^{4}$, triptans and ergotamines, that are also effective for pain and nausea in patients with moderate to severe migraine $^{5}$. Unfortunately, medications are not always effective and when the pharmacologic options fail the patient's quality of life are poor.

Innovative surgical techniques have been developed to decrease or eliminate migraine by deactivating trigger sites. Some trigger sites have been confirmed in migraines and are susceptible to respond to surgery $^{2,6,7}$. These include frontal ${ }^{8}$, temporal ${ }^{9}$, rhinogenic $^{10}$, and occipital ${ }^{11}$ trigger points. To confirm the trigger point as the cause of the patient's migraine, Botulinum toxin Type $A$ is injected in the trigger sites, weakening the muscles, and releasing tension over the nerves. This is based in the fact that patients treated with cosmetic Botulinum toxin have mentioned that their migraine episodes improved or had stopped after the injection ${ }^{12}$. As a result, in case of any decrease in the frequency or intensity of the migraine symptoms, this would predict the effectiveness of the surgery ${ }^{13}$.
Current recommendations indicate that the toxin should be injected on a single trigger site per visit, starting with the most common site ${ }^{14}$. The main problem with this protocol is the large amount of time and the multiple visits to the office required before surgery, making it very expensive. Furthermore, it has been confirmed that the outcomes of the surgery based on the response to Botulinum toxin Type A injection in the trigger sites are similar than those based on clinic interpretation ${ }^{15}$. This is probably due to the vast constellation of signs and symptoms that cause migraine ${ }^{15}$.

The aim of this study is to assess the effectiveness of a modification of the described migraine surgery, as a proof of concept study, to reduce the frequency and intensity of the migraine episodes of our patients.

\section{Patients and methods}

We designed a pilot, proof of concept, and prospective study to analyze the effectiveness of surgical release of trigger nerves in severe frontal or occipital chronic migraines. The study was approved by the Ethics and Investigation Committee of Hospital Universitario "Dr. José Eleuterio González."

The study included patients between the ages of 18-60 years old with a diagnosis of severe chronic frontal or occipital migraine that was received from March to December 2012. These patients had clinical findings of a trigger migraine and were previously treated with medications having unsuccessful results. Diagnostic of migraine was based on the criteria from the American Headache Society by the neurology service of our hospital. All the patients signed a written consent form authorized by the Ethics Committee.

To corroborate that the migraine episode was of trigger nature, an injection of $2 \%$ lidocaine (2cc) was administered subcutaneously in the glabellar and/or occipital areas of the patients during an acute 
migraine attack. If their symptoms decreased or disappeared, they were included in the study.

Patients with coagulopathy, neuropathy, or collagenopathy, with a history of the application of Botulinum toxin Type $A$ in the past 3 months, pregnancy and those who did not sign a consent form were excluded from this study. Elimination criteria included lost from follow-up, automedication with antimigraine pills not approved by the investigators, and any application of Botulinum toxin after the surgical procedure.

\section{Frontal surgical procedure}

An incision was realized in the upper palpebral sulcus and sharp dissection was performed through glabellar muscles (corrugator supercilii and procerus). After localizing and protecting the supratrochlear and supraorbital nerves and vessels, a $1 \mathrm{~cm}^{3}$ block of muscle was resected around the nerves followed by careful hemostasis. Wound was closed with 6-0 nylon running suture figure 1a-e.

\section{Occipital surgical procedure}

We localized the area $3 \mathrm{~cm}$ caudal to the occipital protuberance and $1.5 \mathrm{~cm}$ lateral to the midline. A transverse $4 \mathrm{~cm}$ incision was made. We localized the semispinalis capitis muscle bilaterally and the emergence of the major occipital nerve. A resection of a triangle of fascia ( $1 \mathrm{~cm}$ per side) was performed for a tension-free closure. Careful hemostasis was achieved, and wound closure was accomplished in layers figure 2a-e.

\section{Evaluation}

Patients were evaluated in terms of frequency, intensity, and duration of migraines in a monthly basis for 2 months. The "MIDAS" questionnaire was used to assess pre-operative and post-operative satisfaction ${ }^{16}$.

Complete response to treatment was defined as not having any symptoms within the studied month. Moreover, partial response to treatment was defined as a decrease of more than $50 \%$ in duration, intensity, and frequency of migraine episodes within the studied month?

\section{Results}

Three patients were included in the study. Two female and one male ages ranging from 19 to 52 years old (median 36.6 yo). Both females had a Stage IV occipital migraine (i.e., severe disabling) according to the "MIDAS" questionnaire. The male patient was diagnosed with frontal migraine Stage IV (i.e. severe disabling), treated previously with Botulinum toxin Type A 5 months before his enrollment to the study table 1.

Patient 1 had partial response to treatment with a decrease in duration, frequency, and intensity of migraine attacks in both months. Patient 2 had a
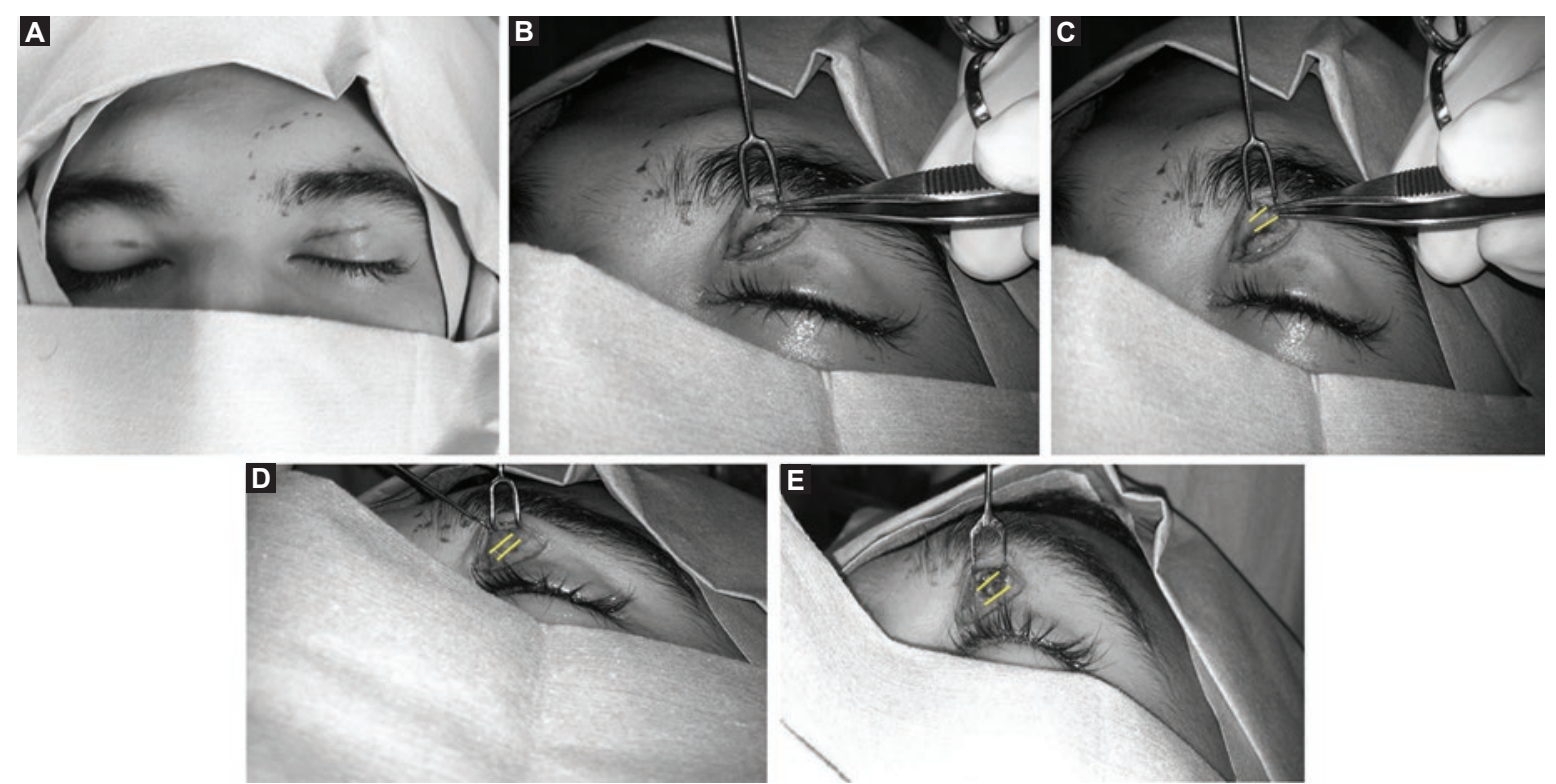

Figure 1. (A) Corrugator supercilii area marked in blue ink. Superior palpebral sulcus previously marked for incision. (B) Corrugator supercilii between clamps. (C) Corrugator supercilii dissected between two yellow lines. (D) Corrugator supercilii between two yellow lines. (E) $1 \mathrm{~cm}^{3}$ block of corrugator supercilii resected between two yellow lines. 

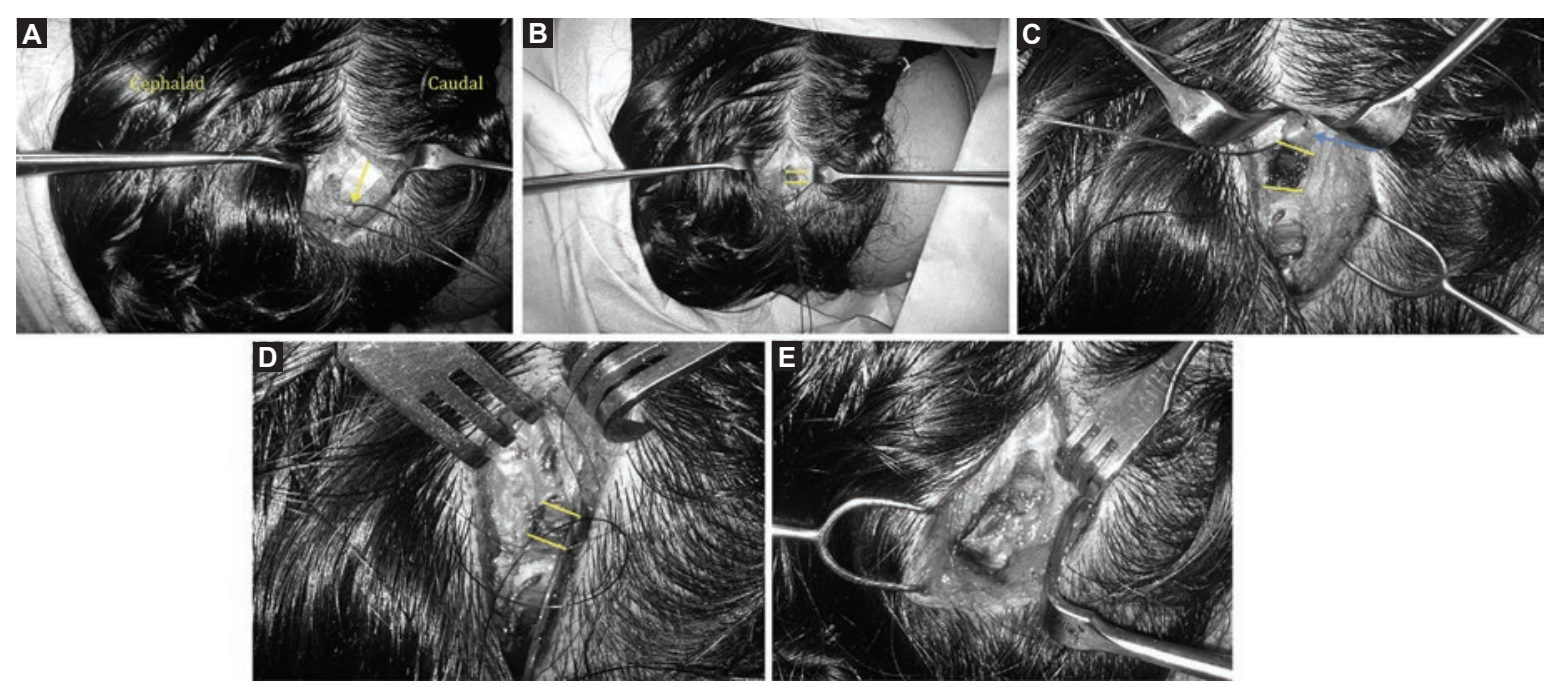

Figure 2. (A) Greater occipital nerve indicated by yellow arrow. (B) Semispinalis capitis muscle between yellow lines. (C) $1 \mathrm{~cm}^{3}$ block of semispinalis capitis muscle between two yellow lines. Blue arrow showing greater occipital nerve. (D) $1 \mathrm{~cm}^{3}$ block of semispinalis muscle resected shown between two yellow lines. (E) Triangle of fascia resected for a tension-free closure (blue dye).

Table 1: Social demographics

\begin{tabular}{lclll}
\hline Sex & Age & $\begin{array}{l}\text { Duration of } \\
\text { symptoms }\end{array}$ & $\begin{array}{l}\text { Type of } \\
\text { migraine }\end{array}$ & $\begin{array}{l}\text { MIDAS } \\
\text { test }\end{array}$ \\
\hline Female & 42 & 20 years & Occipital & Stage IV \\
Male & 18 & 5 years & Frontal & Stage IV \\
Female & 52 & 10 years & Occipital & Stage IV \\
\hline
\end{tabular}

complete response, without presenting any symptoms of migraine in 2 months, even after realizing maneuvers that usually triggered his migraine. Patient 3 had partial response the $1^{\text {st }}$ month and complete response the $2^{\text {nd }}$ month figures 3 and 4 .

In the subjective pain scale, patient 1 improved from a pre-operative rate of 10 to 6.7 in the $1^{\text {st }}$ month and to 7.6 the $2^{\text {nd }}$ month based in a pain blog. Patient 2 did not have pain in the two studied months. Patient 3 improved from a pre-operative rate of 8 to 5 in the $1^{\text {st }}$ month and no pain the $2^{\text {nd }}$ month figure 5 .

\section{Discussion}

Every year billions of dollars are spent on migraine treatment, this could be for prevention, treatment, or in labor days lost. Many therapies have been advocated and many have failed. The pathophysiology is based on two current theories: vasculitis and neurovasculitis. The latter one, being more recently described, is the basis for this study. Thus, accepting that neurovasculitis triggers the supratrochlear, supraorbital, or greater occipital nerves, the intention of the surgery is to prevent this action by releasing the nerves

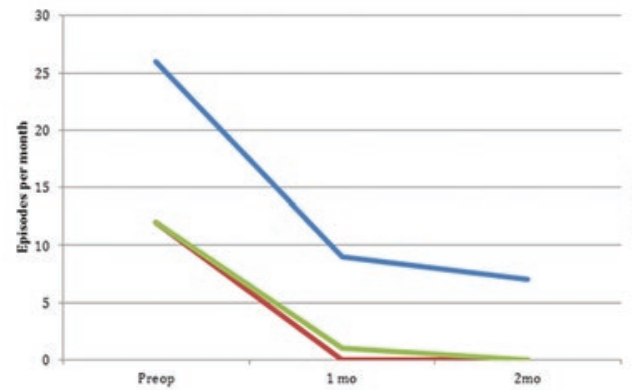

Figure 3. Frequency of episodes per month.

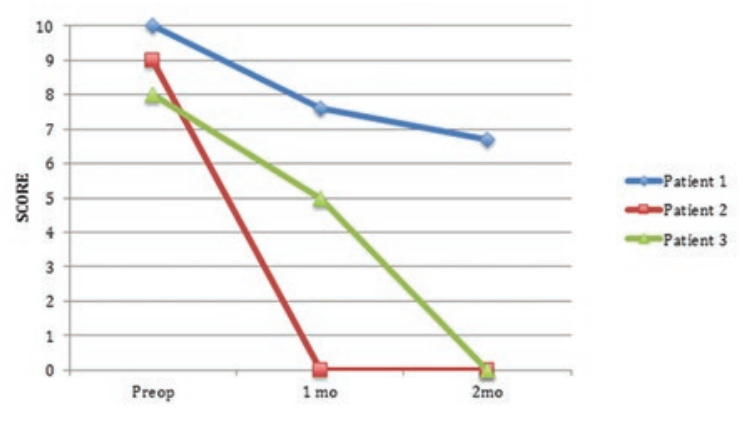

Figure 4. Pain intensity based on an analog score recorded in a daily diary.

from any external pressure created by surrounding muscles.

As previously stated, Dr. Guyuron in Cleveland, $\mathrm{OH}$, has been performing this type of surgeries in patients since 2000 with excellent results ${ }^{6}$. Having that as groundwork, we decided to take a step further and perform surgeries in patients with chronic migraine, with previous unsuccessful medical treatment. 


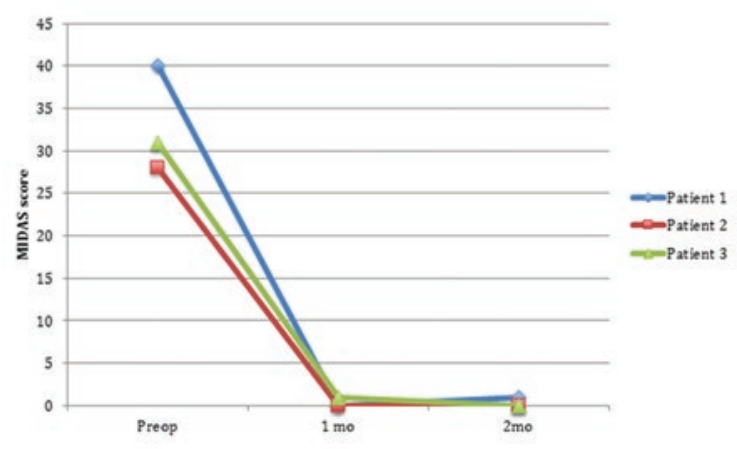

Figure 5. MIDAS score by patient.

The inclusion criteria included patients with diagnosis of frontal or occipital chronic migraine and not temporal or rhinogenic. It was decided in this way because the first ones can be performed with local anesthesia and IV sedation. Thus, their cost is lower making them affordable for our population.

Some authors have described the use of Botulinum toxin Type A in this trigger area with the same results $^{12}$; this was also the foundation for some studies. We are achieving the same results as what Botulinum toxin Type A does, by resecting a small block of $1 \mathrm{~cm}^{3}$ muscle (glabellar muscles and semispinalis capitis) depending the area, but aiming for permanent results. After we released the nerves in the occipital area, we had the appreciation that there was still some tension around the great occipital nerves so we decided to release a triangular incision in the fascia. Afterward, the nerves appeared loose at their emergence areas. Even though these are short-term results, the observed response is promising. Time will tell us if these results are long lasting.

Due to the socioeconomic characteristics of our patients, the routinely use of Botulinum toxin Type $A$ is difficult, if not prohibitive. Thus, we decided to use lidocaine instead into confirm a trigger site since it has been used previously for the treatment of acute migraine $^{17}$. Although it has not been properly studied, we observed a good level of prediction of success of the surgery.

There is a problem with the idiosyncrasy facing this type of surgical procedures by neurologists and patients alike. Since this problem has always been treated with preventive measures or medication, the introduction of an invasive procedure has not been easily accepted by neurologists, even when it has been shown that the surgery leads to good results?

We expect that more patients will accept this type of treatment when the results catch a "word of mouth" phenomenon. In our hospital, every day more patients are asking for this kind of treatment, but not all of them are candidates. It is very important to scrutinize which patients we are going to operate since we could easily start overdiagnosing migraines with trigger areas and consequently obtain underachieving results.

\section{Conclusions}

Surgical treatment in chronic migraines with frontal or occipital trigger areas has excellent results in patients with an incapacitating severe stage diagnosed by the MIDAS questionnaire, in which preventive measures and medication have been administered with unsuccessful aftermath.

There is still a lot of room left to convince the neurologists and patients alike that for certain type of migraines, surgery is a viable and permanent choice of treatment with extraordinary results or at least satisfactory with a very manageable pain.

We still need to study and follow these patients for a longer period of time to determine the long-term effectiveness of this treatment.

\section{Ethical disclosures}

Protection of human and animal subjects. The authors declare that the procedures followed were in accordance with the regulations of the relevant clinical research ethics committee and with those of the Code of Ethics of the World Medical Association (Declaration of Helsinki).

Confidentiality of data. The authors declare that they have followed the protocols of their work center on the publication of patient data.

Right to privacy and informed consent. The authors have obtained the written informed consent of the patients or subjects mentioned in the article. The corresponding author is in possession of this document.

\section{Funding}

The authors did not receive funding to prepare this article.

\section{Conflict of interest}

The authors declared no conflicts of interest.

\section{References}

1. Lipton RB, Bigal ME, Diamond $M$, et al. Migraine prevalence, disease burden, and the need for preventive therapy. Neurology. 2007;68:343-9. 
2. Larson K, Lee M, Davis J, Guyuron B. Factors contributing to migraine headache surgery failure and success. Plast Reconstr Surg. 2011; 128:1069-75

3. Faber C, Garcia RM, Davis J, Guyuron B. A socioeconomic analysis of surgical treatment of migraine headaches. Plast Reconstr Surg. 2012:129:871-7.

4. Gilmore B, Michael M. Treatment of acute migraine headache. Am Fam Phys. 2011;83:271-80.

5. Bartleson JD, Cutrer FM. Migraine update. Diagnosis and treatment Minn Med. 2010;93:36-41.

6. Kung TA, Guyuron B, Cederna PS. Migraine surgery: a plastic surgery solution for refractory migraine headache. Plast Reconstr Surg. 2011; 127:181-9.

7. Guyuron B, Reed D, Kriegler JS, Davis J, Pashmini N, Amini S. A placebo-controlled surgical trial of the treatment of migraine headaches. Plast Reconstr Surg. 2009;124:461-8.

8. Guyuron B, Varghai A, Michelow BJ, Thomas T, Davis J. Corrugator supercilii muscle resection and migraine headaches. Plast Reconstr Surg. 2000;106:429-34.

9. Totonchi A, Pashmini N, Guyuron B. The zygomaticotemporal branch of the trigeminal nerve: an anatomical study. Plast Reconstr Surg. 2005 115:273-7.
10. Novak VJ, Makek M. Pathogenesis and surgical treatment of migraine and neurovascular headaches with rhinogenic trigger. Head Neck. 1992;14:467-72

11. Janis JE, Hatef DA, Reece EM, McCluskey PD, Schaub TA, Guyuron B. Neurovascular compression of the greater occipital nerve: implications for migraine headaches. Plast Reconstr Surg. 2010;126:1996-2001.

12. Guyuron B, Tucker T, Kriegler J. Botulinum toxin a and migraine surgery. Plast Reconstr Surg. 2003;112:171S-3.

13. Liu MT, Armijo BS, Guyuron B. A comparison of outcome of surgical treatment of migraine headaches using a constellation of symptoms versus botulinum toxin type A to identify the trigger sites. Plast Reconstr Surg. 2012:129:413-9.

14. Behmand RA, Tucker T, Guyuron B. Single-site botulinum toxin type A injection for elimination of migraine trigger points. Headache. 2003; 43:1085-9.

15. Guyuron B, Watkins F, Totonchi A. Modified temporal incision for facial rhytidectomy: an 18-year experience. Plast Reconstr Surg. 2005;115: 609-16.

16. Poggi JT, Grizzell BE, Helmer SD. Confirmation of surgical decompression to relieve migraine headaches. Plast Reconstr Surg. 2008;122:115-22.

17. Amparan-Estrada S. Management of acute migraine headache with lidocaine. Plast Reconstr Surg. 2005;116:335. 